\title{
Thermal Imaging Is a Noninvasive Alternative to PET/CT for Measurement of Brown Adipose Tissue Activity in Humans
}

\author{
James Law ${ }^{1}$, David E. Morris ${ }^{2}$, Chioma Izzi-Engbeaya ${ }^{3}$, Victoria Salem ${ }^{3}$, Christopher Coello ${ }^{4}$, Lindsay Robinson ${ }^{1}$, \\ Maduka Jayasinghe ${ }^{3}$, Rebecca Scott ${ }^{3}$, Roger Gunn ${ }^{4}$, Eugenii Rabiner ${ }^{4,5}$, Tricia Tan ${ }^{3}$, Waljit S. Dhillo ${ }^{3}$, Stephen Bloom ${ }^{3}$, \\ Helen Budge ${ }^{1}$, and Michael E. Symonds ${ }^{1,6}$ \\ ${ }^{1}$ Early Life Research Unit, Division of Child Health, Obstetrics, and Gynaecology, School of Medicine, University of Nottingham, \\ Nottingham, United Kingdom; ${ }^{2}$ Bioengineering Research Group, Faculty of Engineering, University of Nottingham, Nottingham, \\ United Kingdom; ${ }^{3}$ Division of Diabetes, Endocrinology, and Metabolism, Imperial College, London, United Kingdom; ${ }^{4}$ Imanova \\ Centre for Imaging Sciences, Imperial College, London, United Kingdom; ${ }^{5}$ Centre for Neuroimaging Sciences, King's College, \\ London, United Kingdom; and ${ }^{6}$ Nottingham Digestive Disease Centre and Biomedical Research Centre, School of Medicine, \\ University of Nottingham, Nottingham, United Kingdom
}

\begin{abstract}
Obesity and its metabolic consequences are a major cause of morbidity and mortality. Brown adipose tissue (BAT) utilizes glucose and free fatty acids to produce heat, thereby increasing energy expenditure. Effective evaluation of human BAT stimulators is constrained by the current standard method of assessing BATPET/CT - as it requires exposure to high doses of ionizing radiation. Infrared thermography (IRT) is a potential noninvasive, safe alternative, although direct corroboration with PET/CT has not been established. Methods: IRT and ${ }^{18} \mathrm{~F}-\mathrm{FDG}$ PET/CT data from 8 healthy men subjected to water-jacket cooling were directly compared. Thermal images were geometrically transformed to overlay PET/CT-derived maximum intensity projection (MIP) images from each subject, and the areas with the most intense temperature and glucose uptake within the supraclavicular regions were compared. Relationships between supraclavicular temperatures $\left(T_{S C R}\right)$ from IRT and the metabolic rate of glucose uptake (MR(gluc)) from PET/CT were determined. Results: Glucose uptake on MR(gluc) $)_{\text {MIP }}$ was found to correlate positively with a change in $\mathrm{T}_{\mathrm{SCR}}$ relative to a reference region $\left(r^{2}=0.721 ; P=0.008\right)$. Spatial overlap between areas of maximal MR(gluc) $)_{\text {MIP }}$ and maximal $\mathrm{T}_{\mathrm{SCR}}$ was $29.5 \% \pm 5.1 \%$. Prolonged cooling, for $60 \mathrm{~min}$, was associated with a further $\mathrm{T}_{\mathrm{SCR}}$ rise, compared with cooling for 10 min. Conclusion: The supraclavicular hotspot identified on IRT closely corresponded to the area of maximal uptake on PET/CT-derived MR(gluc) MIP images. Greater increases in relative $T_{S C R}$ were associated with raised glucose uptake. IRT should now be considered a suitable method for measuring BAT activation, especially in populations for whom PET/CT is not feasible, practical, or repeatable.
\end{abstract}

Key Words: brown adipose tissue; thermal imaging; infrared thermography; PET/CT

J Nucl Med 2018; 59:516-522

DOI: $10.2967 /$ jnumed.117.190546

Received May 30, 2017; revision accepted Jul. 12, 2017.

For correspondence contact: Michael E. Symonds, Early Life Research Unit, Division of Child Health, Obstetrics, and Gynaecology, School of Medicine, University Hospital, University of Nottingham, Nottingham, NG7 2UH United Kingdom.

E-mail: michael.symonds@nottingham.ac.uk

Published online Sep. 14, 2017.

COPYRIGHT (C 2018 by the Society of Nuclear Medicine and Molecular Imaging.
$\mathbf{O}$ besity is a leading global health concern, with no effective drug treatments currently available. An adverse metabolic profile, including insulin resistance and raised blood lipids, is a common pathway to many of the consequences of obesity. Brown adipose tissue (BAT) is a major effector of adaptive thermogenesis and an attractive antiobesity drug target (1). It is a highly metabolically active organ that utilizes glucose and free fatty acids and is able to release chemical energy efficiently as heat by uncoupling mitochondrial respiration from adenosine triphosphate production (2). Increased BAT activity results in raised energy expenditure, improved glycemic control, and an improved blood lipid profile (3).

In recent years, after the rediscovery of BAT in adult humans (4-8), it has been the focus of intense research. However, replication of the promising results from animal studies has been slow (9). This is due, in part, to difficulties in measuring BAT activity directly in humans. Because of the variable anatomic position of BAT, close to major vessels, safe and routine biopsy is difficult, causing imaging to become the preferred method of BAT quantification. The standard method of BAT imaging remains PET/CT, which exposes participants to a significant radiation dose and is therefore not suitable for studies with repeated measures, large numbers of healthy volunteers, or children. Measurements using PET/CT are also limited to fasting subjects (10).

An alternative imaging technique, infrared thermography (IRT), makes use of the heat-emitting properties of BAT and the relatively superficial position of the supraclavicular depot, one of the largest BAT depots in adults (7). Using IRT, several research groups have shown a specific rise in supraclavicular temperatures $\left(\mathrm{T}_{\mathrm{SCR}}\right)$ after introduction of a cool stimulus (11-14). IRT has the advantage of being able to measure real-time activation and can be used to gather repeated measures in large numbers of healthy subjects irrespective of age and nutritional status (11).

To date, IRT has not been validated against the current gold standard, ${ }^{18} \mathrm{~F}-\mathrm{FDG}$ PET/CT. Although the results from multiple previous IRT studies are consistent with the measurement of BAT, the lack of data directly comparing results between PET/CT and IRT in the same subjects has remained a limitation of the technique. Using novel IRT analysis methods, as well as PET/CT analysis techniques additional to those used by Salem et al. (13), we explored the anatomic and functional relationship between alternative measures of BAT in individual participants. For the first time, to our 
knowledge, we show here that the area identified as overlying BAT using IRT closely corresponds to the area of maximal glucose uptake on PET/CT and that the higher the glucose uptake on PET/CT the better the agreement.

\section{MATERIALS AND METHODS}

\section{Subjects}

To determine the correlation between BAT activity measured by PET/CT and IRT, 8 healthy men known to be BAT-positive on PET/CT (13) (mean age, 23.5 y; range, 18-35 y; mean body mass index, 22.0 $\mathrm{kg} / \mathrm{m}^{2}$; range $19.3-23.0 \mathrm{~kg} / \mathrm{m}^{2}$ ) underwent PET/CT and IRT sessions as part of a study approved by the London Central Ethics and Research Committee (13/LO/0925), registered with ClinicalTrials.gov (NCT01935791), and performed in accordance with the Declaration of Helsinki. Written informed consent was obtained from subjects before enrollment in the study. Participants who were BAT-negative on the initial PET/CT scan (13) were not included in the analysis because of the small size of the group $(n=3)$.

\section{Study Visits}

As previously described (13), participants attended an initial IRT session and an initial PET/CT session. For both visits, the volunteers wore a pair of light cotton trousers with a cooling vest surrounding the torso, away from the supraclavicular region. After acclimatization, cold water at $8^{\circ} \mathrm{C}(13)$ was pumped through the cooling vest to stimulate BAT.

In summary, during the thermal imaging session, images were captured during acclimatization; over the first 10 min of cooling (initial period), which represents the period of maximal BAT activation from the resting state (12); and after prolonged stimulation (final period) (Fig. 1). Images were acquired using a FLIR T440bx infrared camera (FLIR Systems). During the PET/CT visit, $180 \mathrm{MBq}$ of ${ }^{18} \mathrm{~F}-\mathrm{FDG}$ were injected after water-vest cooling, and a 60-min dynamic emission scan was obtained with an axial field of view from mandible to mid thorax (13).

All volunteers attended a second thermal imaging session without cold stimulation (IRT vehicle session), and 4 volunteers who were BAT-positive on the first PET/CT scan underwent a further PET/CT imaging session, without cold stimulation (PET/CT vehicle session). Thermal and PET/CT images were acquired as before.

\section{Analysis of IRT}

Thermal images (TIs) acquired by IRT at 5-s intervals were analyzed from each period of imaging for both IRT sessions. We developed a semiautomated method for analysis of TIs to allow the efficient analysis of large numbers of images in a systematic and reproducible manner by first converting the TIs to the nonproprietary Portable Network Graphic format, then identifying the supraclavicular regions of interest (ROIs), and finally processing the data within the ROIs.

The TIs were converted using our custom-built Thermal-Imaging Technical Conversion Hub, a Raspberry Pi-based device that extracts the raw data from the TI and saves it in an openly accessible format from which temperature data can be calculated $(15,16)$. Our method for converting the raw radiometric data to temperature data produces results identical to those obtained by FLIR's proprietary software (data not shown).

Left and right supraclavicular ROIs were defined as previously described (12). In contrast to previous methods (12), this simply required each image (Fig. 2A) to be labeled with 5 key points, corresponding to the apices of the ROIs (Fig. 2B). The medial and inferior borders of the ROI were defined as straight lines between the appropriate apices. The contour of the neck was defined programmatically by identifying the temperature gradient between the volunteer and the background. This approach represents a significant improvement on previously published methods, in which the lateral border of the ROI is approximated by a simple straight line (17) or is painstakingly identified between manually plotted points (12).

The hottest $10 \%$ of points within each ROI were identified, and the medians of these points were calculated (equivalent to the 95 th percentile) $(11,12,18)$. Corresponding graphical output allowed clear visualization of the identified hotspot (Fig. 2B). A reference region consisting of a circle 10 pixels in diameter immediately below the central apex of the ROIs was analyzed for comparison. A moving average (period 5) was applied to the resulting time series to reduce the effect of natural variation in measurements. The main outcome measures for IRT were base $\mathrm{T}_{\mathrm{SCR}}$ (mean of the first minute of stimulation), peak $\mathrm{T}_{\mathrm{SCR}}$ (maximal $\mathrm{T}_{\mathrm{SCR}}$ within a given period), and $\Delta \mathrm{T}_{\mathrm{SCR}}$ (peak $\mathrm{T}_{\mathrm{SCR}}$ - base $\mathrm{T}_{\mathrm{SCR}}$ ), all calculated for the right ROI (11) over the first $10 \mathrm{~min}$ of cooling relative to the reference region $(11,18)$. Secondary outcomes included analysis of absolute $\mathrm{T}_{\mathrm{SCR}}$ values as well as comparison of left and right ROIs.

Videos of change in skin temperature over time, relative to the baseline image, were compiled. Pixels were averaged over 3 sequential images, and sequential frames were registered to the baseline image by applying an automatically calculated geometric transformation consisting of translation, rotation, and scale. Unchanged pixels were displayed as white, colder pixels as progressively blue and then black, and warmer pixels as progressively red and then yellow (Supplemental Video 1; supplemental materials are available at http://jnm.snmjournals.org).

\section{Analysis of PET/CT}

Regional estimates of the metabolic rate of glucose [MR(gluc $\left.)_{\mathrm{BAT}}\right]$ were calculated as previously described (13). In addition, 2 coronal maximum-intensity-projection (MIP) images for each volunteer were calculated from the PET/CT data for each visit, one for the CT image $\left(\mathrm{CT}_{\mathrm{MIP}}\right)$ and one for the MR(gluc) values (MR(gluc) $)_{\mathrm{MIP}}$ ) (19). MIP images are 2-dimensional representations of 3-dimensional data, with the value of each point determined by the maximum intensity of the data along a point-line perpendicular to the projected plane, that is:

$$
\begin{gathered}
\mathrm{CT}_{\mathrm{MIP}}(x, y)=\max _{\mathrm{z}}(\mathrm{CT}(x, y, z)), \text { and } \\
\operatorname{MR}(\text { gluc })_{\mathrm{MIP}}(x, y)=\max _{\mathrm{z}}(\operatorname{MR}(\text { gluc })(x, y, z)) .
\end{gathered}
$$

A composite of the 2 MIP images was used in the graphical output (Fig. 2). The region of the greatest $10 \%$ of $\mathrm{MR}(\mathrm{gluc})_{\mathrm{MIP}}$ was identified, and the median of these values was calculated for comparison with the results of IRT.

\section{PET/CT/IRT Comparison}

To identify similarities and differences between the data acquired from PET/CT and the data acquired from IRT, the TI was warped onto the MR(gluc) MIP image from the same participant (Fig. 2). The comparative TI was a mean composite of the last 3 images
FIGURE 1. IRT imaging protocol annotated with IRT outcomes. Acclimatization = imaging period during acclimatization; initial $=$ imaging period during first $10 \mathrm{~min}$ of stimulation; final = imaging period after stimulation for $\sim 1 \mathrm{~h}$. 


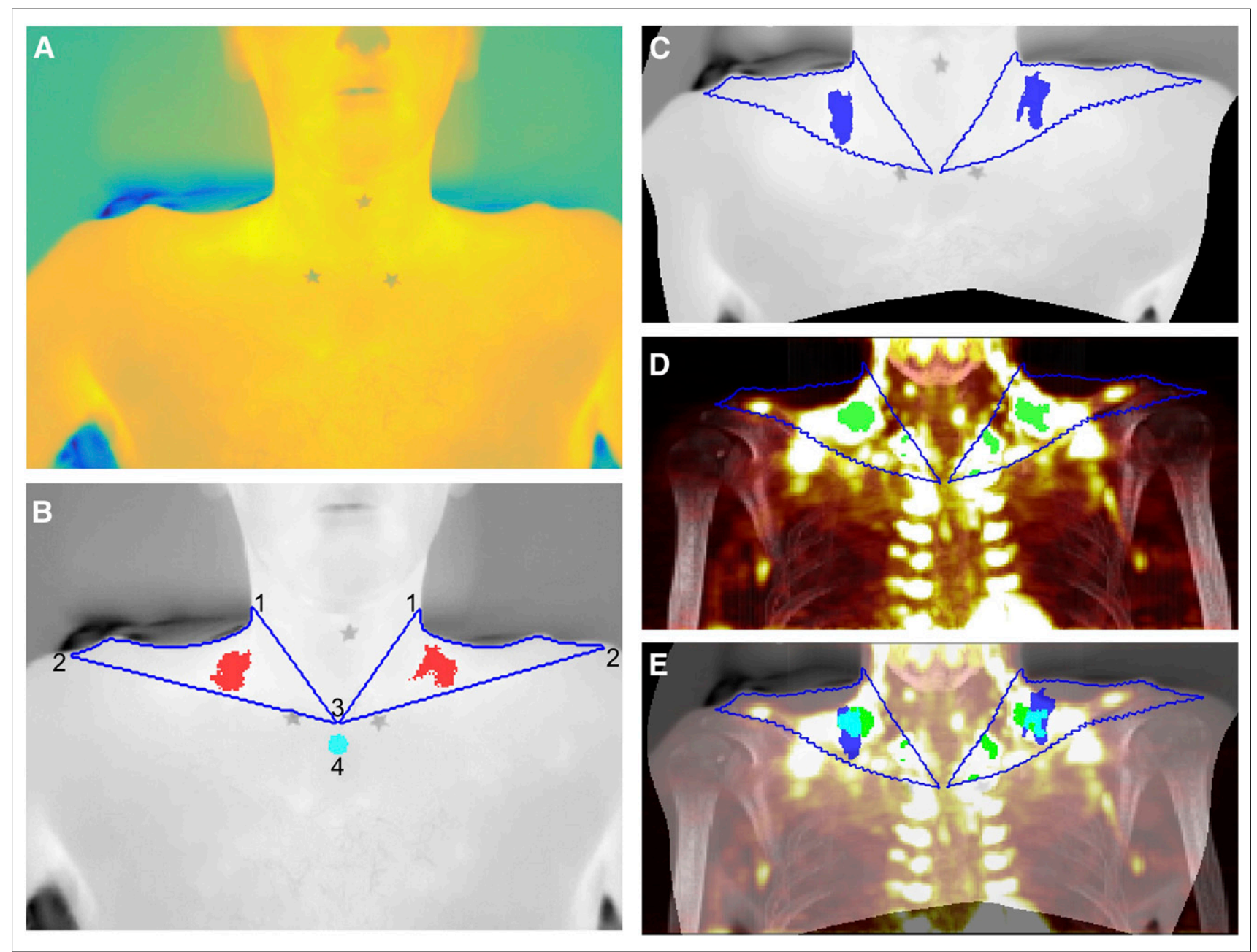

FIGURE 2. Mapping of TI to PET/CT. (A) Apices of ROls identified on original TI. (B) Contour of ROI (blue) and hottest $10 \%$ of pixels (red) identified, with contour of neck precisely defined using automated process: left and right superolateral apices (1), acromioclavicular apices (2), sternal apex (3), and reference area (4). (C) TI after warping by Iwm transformation calculated after identification of control-point pairs. (D) Warped contour superimposed on MIP with most intense $10 \%$ of pixels highlighted (green). (E) Final composite image with warped TI superimposed on MIP image and hottest pixels from TI (blue), most intense pixels from MIP (green), and overlap (cyan) demonstrating close anatomic proximity.

from the initial imaging session (i.e., after $10 \mathrm{~min}$ of stimulation)

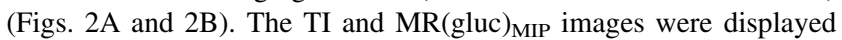
beside each other, and control-point pairs were defined, identifying corresponding anatomic points. Seventy control-point pairs were identified in the supraclavicular region of each pair of images, with additional nonsupraclavicular points depending on the framing of the images. A locally weighted mean transformation (20) mapping was created by inferring a second-degree polynomial at each control-point based on the 16 closest points and using a locally weighted average of these polynomials. This mapping was applied to the TI (Fig. 2C).

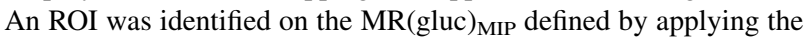
locally weighted mean transformation to the contour of the ROI of the TI and superimposing this on MR(gluc) $)_{\text {MIP }}$ The greatest $10 \%$ of values within the ROI were identified for the MR(gluc) $)_{\mathrm{MIP}}$ and the median of these points was calculated in a similar manner to that described for the TI (Fig. 2D).

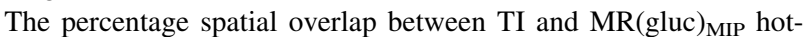
spots was calculated and displayed as an image (Fig. 2E). Since the TI

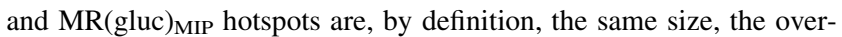
lap is the number of pixels that the hotspots have in common divided by the total number of pixels of either hotspot).

\section{Statistical Analysis}

After conversion of the TI to the Portable Network Graphic format, further graphical analysis was performed using MATLAB, version 2016a (The Mathworks Inc.). The apices were identified using a custom-built graphic-user interface within MATLAB, and a second script was written to undertake the analysis. The inbuilt MATLAB function imregister was used to register sequential images to compile the videos, cpselect was used to identify control-point pairs, and fitgeotrans was used to fit an lwm transformation object to the controlpoint pairs. Trends in $\mathrm{T}_{\mathrm{SCR}}$ over time and correlations between variables were analyzed using R: A Language and Environment for Statistical Computing, version 3.2.3 (R Core Team).

\section{RESULTS}

\section{TI Analyses}

Analyses of TIs from the initial imaging period of the cooling session showed that participants had a base $\mathrm{T}_{\mathrm{SCR}}$ of $35.1^{\circ} \mathrm{C} \pm 0.3^{\circ} \mathrm{C}$ at the start of stimulation, with a peak temperature of $35.2^{\circ} \mathrm{C} \pm 0.3^{\circ} \mathrm{C}$ during the first $10 \mathrm{~min}$ of stimulation (change during first $10 \mathrm{~min}$ of stimulation $\left[\Delta_{10} \mathrm{~T}_{\mathrm{SCR}}\right], 0.1^{\circ} \mathrm{C} \pm 0.03^{\circ} \mathrm{C}$ ) (Table 1). Base $\mathrm{T}_{\mathrm{SCR}}$ was 
TABLE 1

IRT Analysis: Absolute $\mathrm{T}_{\mathrm{SCR}}$ and $\mathrm{T}_{\mathrm{SCR}}$ Relative to Sternal Reference Region

\begin{tabular}{lccc}
\hline \multicolumn{1}{c}{$\mathrm{T}_{\mathrm{SCR}}\left({ }^{\circ} \mathrm{C}\right)$} & Vehicle session & Cold session & \\
\hline Absolute & & $35.1 \pm 0.29$ & 0.09 \\
Base & $35.7 \pm 0.07$ & $35.2 \pm 0.29$ & 0.09 \\
Peak (initial) & $35.8 \pm 0.06$ & $0.1 \pm 0.03$ & 0.64 \\
Change over first 10 min of cooling & $0.1 \pm 0.03$ & $35.4 \pm 0.25$ & 0.06 \\
Peak (initial and final) & $35.9 \pm 0.08$ & $35.1 \pm 0.30$ & 0.11 \\
At 10 min of cooling & $35.6 \pm 0.07$ & $35.3 \pm 0.25$ & \\
In final minute of cooling & $35.7 \pm 0.08$ & & \\
Relative & & $1.9 \pm 0.24$ & 0.09 \\
Base & $1.3 \pm 0.13$ & $2.2 \pm 0.27$ & 0.01 \\
Peak (initial) & $1.4 \pm 0.13$ & $0.3 \pm 0.05$ & 0.01 \\
Change over first 10 min of cooling & $0.2 \pm 0.03$ & $2.7 \pm 0.29$ & 0.04 \\
Peak (initial and final) & $1.5 \pm 0.14$ & $2.2 \pm 0.26$ & 0.004 \\
At 10 min of cooling & $1.4 \pm 0.14$ & $2.6 \pm 0.27$ & 0.0004
\end{tabular}

Data are mean \pm SEM from 8 men.

$1.9^{\circ} \mathrm{C} \pm 0.2^{\circ} \mathrm{C}$ above the sternal reference region, with a peak difference of $2.2^{\circ} \mathrm{C} \pm 0.3^{\circ} \mathrm{C}$ during the first $10 \mathrm{~min}$ of stimulation $\left(\Delta_{10} \mathrm{~T}_{\mathrm{SCR}}, 0.3^{\circ} \mathrm{C} \pm 0.05^{\circ} \mathrm{C}\right)$. The peak $\mathrm{T}_{\mathrm{SCR}}$ of the initial imaging period alone was significantly lower than the peak $\mathrm{T}_{\mathrm{SCR}}$ during the initial and final imaging periods combined (initial only, $35.2^{\circ} \mathrm{C} \pm$ $0.3^{\circ} \mathrm{C}$; both, $35.4^{\circ} \mathrm{C} \pm 0.2^{\circ} \mathrm{C} ; P=0.03$ ). Similarly, the mean $\mathrm{T}_{\mathrm{SCR}}$ over the last minute of the initial period of stimulation was significantly lower than the mean $\mathrm{T}_{\mathrm{SCR}}$ over the last minute of the final imaging session $\left(35.1 \pm 0.3^{\circ} \mathrm{C}\right.$ vs. $35.3 \pm 0.2^{\circ} \mathrm{C}$, respectively; $\left.P=0.03\right)$.

There were trends toward a decreased base $\mathrm{T}_{\mathrm{SCR}}$ from the vehicle compared with the cooling session (vehicle, $35.7^{\circ} \mathrm{C} \pm 0.07^{\circ} \mathrm{C}$; cooling, $35.1^{\circ} \mathrm{C} \pm 0.3^{\circ} \mathrm{C} ; P=0.09$ ) and lower peak $\mathrm{T}_{\mathrm{SCR}}$ (vehicle, $35.8^{\circ} \mathrm{C} \pm 0.06^{\circ} \mathrm{C}$; cooling, $35.2^{\circ} \mathrm{C} \pm 0.3^{\circ} \mathrm{C} ; P=0.09$ ) but no difference in $\Delta_{10} \mathrm{~T}_{\mathrm{SCR}}$ (vehicle, $0.1^{\circ} \mathrm{C} \pm 0.03^{\circ} \mathrm{C}$; cooling, $0.1^{\circ} \mathrm{C} \pm$ $\left.0.03^{\circ} \mathrm{C} ; P=0.64\right)$. When compared with the reference region, however, base $\mathrm{T}_{\mathrm{SCR}}$ (vehicle, $1.4^{\circ} \mathrm{C} \pm 0.15^{\circ} \mathrm{C}$; cooling, $2.1^{\circ} \mathrm{C} \pm$ $0.23^{\circ} \mathrm{C} ; P=0.008$ ), peak $\mathrm{T}_{\mathrm{SCR}}$ (vehicle, $1.5^{\circ} \mathrm{C} \pm 0.15^{\circ} \mathrm{C}$; cooling, $2.4^{\circ} \mathrm{C} \pm 0.26^{\circ} \mathrm{C} ; P=0.006$ ), and $\Delta_{10} \mathrm{~T}_{\mathrm{SCR}}$ (vehicle, $0.1^{\circ} \mathrm{C} \pm$ $0.03^{\circ} \mathrm{C}$; cooling, $0.3^{\circ} \mathrm{C} \pm 0.04^{\circ} \mathrm{C} ; P=0.007$ ) were all significantly increased by cooling.

\section{Overlap}

Representative images of the process are shown in Figure 2. TI

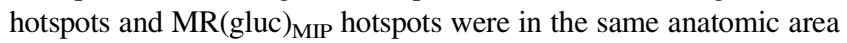
of the ROIs (Fig. 2E). The overlap between the area of maximal glucose uptake on MR(gluc) MIP $_{\text {and the warmest pixels on TI was }}$ $29.5 \%$, respectively (range, $11.6 \%-55.5 \%$; Table 2 ). Images from participants who underwent a PET/CT vehicle session demonstrated that, in the absence of cooling activation of BAT, the overlap between the hotspots was significantly less (cooling, $27.9 \% \pm 6.2 \%$ overlap; vehicle, $6.3 \% \pm 3.1 \%$ overlap; $P=0.009$ ) (Table 2 ).

\section{Relationship Between Hotspots on PET/CT and IRT}

The linearity of the relationship between the IRT and PET/CT outcomes from cooling sessions is given in Table 3. There were strong positive correlations between relative $\Delta_{10} \mathrm{~T}_{\mathrm{SCR}}$ and both
$\operatorname{MR}(\text { gluc })_{\mathrm{MIP}}\left(r^{2}=0.721 ; P=0.008\right)$ and $\mathrm{MR}(\text { gluc })_{\mathrm{BAT}}\left(r^{2}=\right.$ $0.583 ; P=0.027)$. Absolute $\mathrm{T}_{\mathrm{SCR}}$ measurements and relative base and peak $\mathrm{T}_{\mathrm{SCR}}$ did not significantly correlate with $\mathrm{MR}(\text { gluc })_{\mathrm{MIP}}$ or $\operatorname{MR}(\text { gluc })_{\text {BAT }}$.

All 4 participants who had both cold-activated and vehicle PET/ CT scans had an increase in both relative $\Delta_{10} \mathrm{~T}_{\mathrm{SCR}}$ and MR(gluc) $)_{\mathrm{MIP}}$ during cooling, compared with the control session (Fig. 3).

TABLE 2

Percentage Spatial Overlap Between MIP and TI

\begin{tabular}{|c|c|c|}
\hline \multirow[b]{2}{*}{ Participant } & \multicolumn{2}{|c|}{ Overlap (\%) } \\
\hline & Cold & Vehicle \\
\hline$A$ & 31.6 & \\
\hline $\mathrm{B}^{*}$ & 11.6 & 0.1 \\
\hline $\mathrm{C}^{*}$ & 36.6 & 8.4 \\
\hline $\mathrm{D}$ & 55.5 & \\
\hline$E$ & 14.3 & \\
\hline $\mathrm{F}^{\star}$ & 38.5 & 14.1 \\
\hline $\mathrm{G}^{*}$ & 24.9 & 2.6 \\
\hline $\mathrm{H}$ & 22.9 & \\
\hline Mean \pm SEM & $29.5 \pm 5.1$ & \\
\hline${ }^{*}$ Mean \pm SEM & $27.9 \pm 6.2$ & $6.3 \pm 3.1$ \\
\hline \multicolumn{3}{|c|}{ 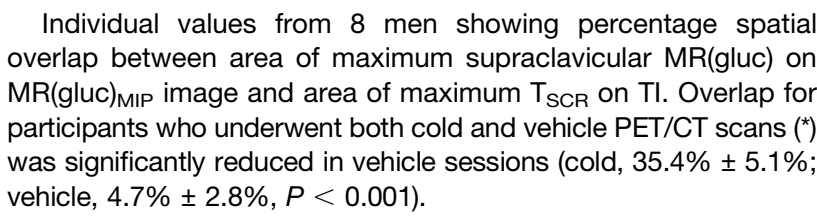 } \\
\hline
\end{tabular}


TABLE 3

Correlation Between IRT Outcome Variables and PET/CT Measures

\begin{tabular}{|c|c|c|c|}
\hline Parameter & $\begin{array}{l}\text { IRT outcome } \\
\text { (right ROI) }\end{array}$ & MR(gluc) $)_{\text {MIP }}$ & $\mathrm{MR}$ (gluc) BAT $_{\text {B }}$ \\
\hline \multirow[t]{3}{*}{ Relative } & Base $T_{S C R}$ & 0.280 (NS) & 0.003 (NS) \\
\hline & Peak $\mathrm{T}_{\mathrm{SCR}}$ (initial) & 0.386 (NS) & 0.032 (NS) \\
\hline & $\Delta_{10} T_{S C R}$ & $0.721^{*}$ & $0.583^{\dagger}$ \\
\hline \multirow[t]{3}{*}{ Absolute } & Base $T_{S C R}$ & 0.118 (NS) & $0.443^{\ddagger}$ \\
\hline & Peak $T_{\text {SCR }}$ (initial) & 0.087 (NS) & $0.406^{\ddagger}$ \\
\hline & $\Delta_{10} \mathrm{~T}_{\mathrm{SCR}}$ & 0.214 (NS) & 0.056 (NS) \\
\hline
\end{tabular}

${ }^{\star} P<0.01$

${ }^{\dagger} P<0.05$

${ }^{\ddagger} P<0.1$.

$\mathrm{NS}=$ not statistically significant.

Values are $r^{2}$, square of Pearson coefficient for 8 male volunteers.

Stronger correlations with PET/CT outcomes were seen for the right ROI than the left (Table 4). The left ROI demonstrated a strong positive correlation between $\mathrm{MR}(\mathrm{gluc})_{\mathrm{MIP}}$ and relative $\Delta_{10} \mathrm{~T}_{\mathrm{SCR}}\left(r^{2}=0.698 ; P=0.010\right)$ but not with other relative IRT outcomes or with MR(gluc) $\mathrm{BAT}$.

\section{DISCUSSION}

IRT is increasingly being used to assess BAT activation and has found an important role in the imaging of healthy volunteers and children, in repeated imaging, and in studies not conducted on fasting subjects (10)—situations in which exposure to ionizing radiation must be minimized. Despite this increasing use, definitive evidence that IRT can measure BAT activity has been lacking. Even studies that have utilized both techniques have done so in a way that does not allow direct comparison (21). We demonstrate here that there is anatomic overlap of the area of maximum temperature measured using IRT and the projected area of maximum glucose uptake on PET. IRT correlates strongly with MR(gluc) from PET/CT. Indeed, since ${ }^{18} \mathrm{~F}$-FDG PET/CT measures glucose uptake and not thermogenic capacity per se (22), greater correlations would not reasonably be expected.

The measure of BAT function obtained by PET/CT is therefore different from that obtained by IRT: glucose uptake as opposed to heat production. The question of which measure is the optimum index of BAT function remains to be fully answered. We observed that subjects who were BAT-positive on PET/CT exhibited a similar magnitude of BAT function on IRT. Furthermore, PET/CT is usually conducted on fasting subjects, because after the subject eats, uptake in BAT is largely masked by the much greater uptake in skeletal muscle (10). It has been suggested that eating, per se, stimulates BAT function (23), and to date, we have been able to detect a positive IRT result in all subjects measured $(n>200)$. Taken together, these findings indirectly support those from repeated PET/ $\mathrm{CT}$, in which most subjects appear to be BAT-positive on at least one scan (24). In addition, as with the reduced BAT activity in obese adults as measured with PET/CT (25) we have previously observed a reduction in BAT activity with increasing BMI percentile in children (11). Future work comparing differences between IRT and
PET/CT measures may indeed offer novel insights into different components of BAT activation.

Previous papers have often used absolute $\mathrm{T}_{\mathrm{SCR}}$ as the primary outcome. However, many factors may affect $\mathrm{T}_{\mathrm{SCR}}$ and even cause it to fall (18). In many cases, the magnitude of the effect on $\mathrm{T}_{\mathrm{SCR}}$ is sufficient to overcome any counteracting factors, but it is clear that true, relative warming is best demonstrated by comparing the $\mathrm{T}_{\mathrm{SCR}}$ with a reference region. We have used a region on the sternum, but alternatives, such as mean skin temperature (18), may allow more subtle effects to be revealed. However, even with the addition of a simple reference region, the true relationship between the two

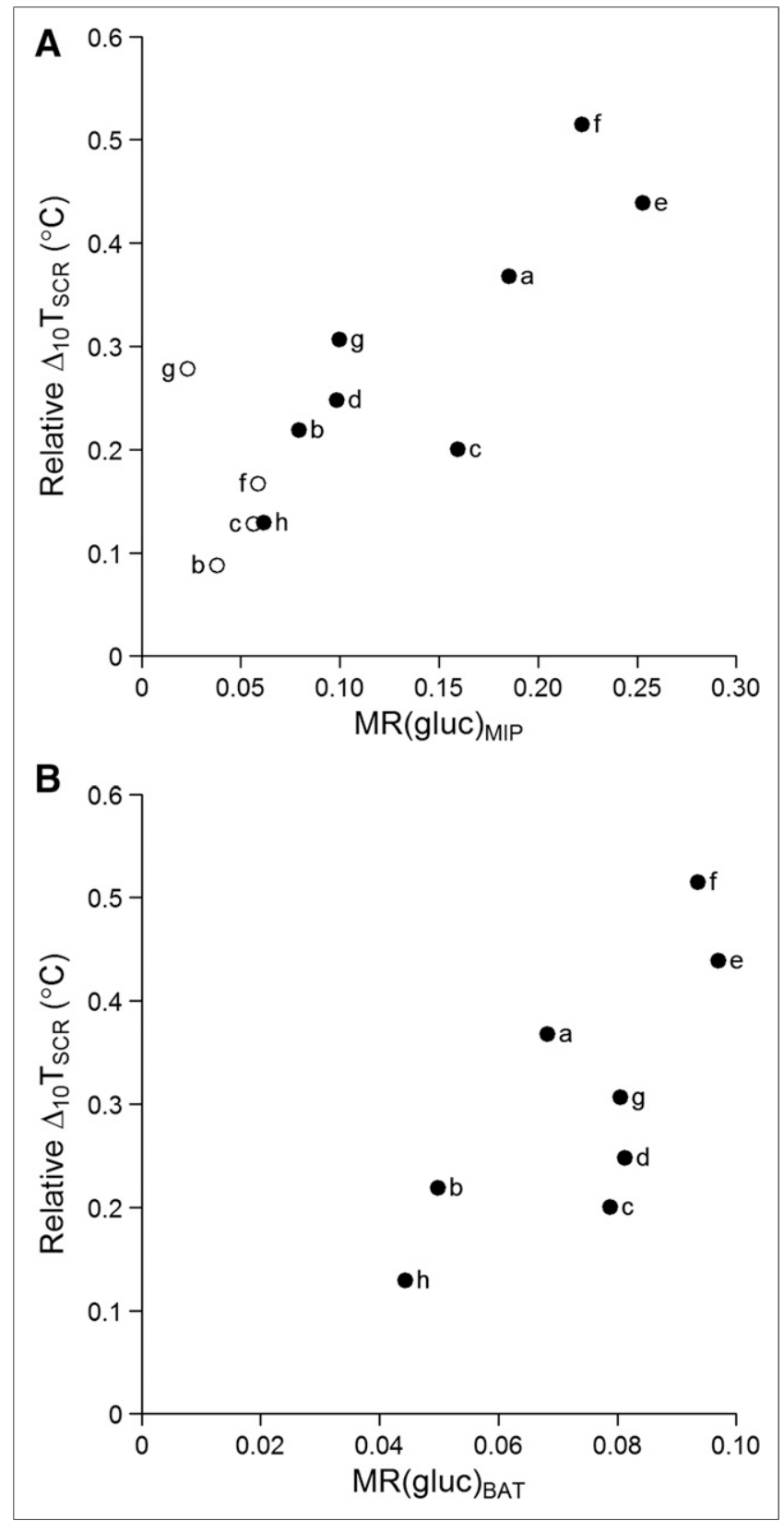

FIGURE 3. $\Delta_{10} T_{S C R}$ (relative to sternal reference) against glucose uptake on PET/CT. Correlation is shown between BAT activity measured with IRT, median MR(gluc) $)_{\text {MIP }}$ hotspot value $\left(r^{2}=0.721 ; P=0.008\right)(A)$, and MR(gluc) $)_{\mathrm{BAT}}\left(r^{2}=0.583 ; P=0.027\right)(\mathrm{B}) . \mathrm{O}=$ control; $\bullet=$ cooling. 
TABLE 4

Correlation Between IRT Outcome Measures for Left and Right ROls and PET/CT Measures

\begin{tabular}{|c|c|c|c|}
\hline PET/CT outcome & IRT outcome (relative to reference region) & Left ROI & Right ROI \\
\hline \multirow[t]{3}{*}{ MR(gluc) $)_{M I P}$} & Base $T_{S C R}$ & 0.172 (NS) & 0.280 (NS) \\
\hline & Peak $T_{\text {SCR }}$ (initial) & 0.239 (NS) & $0.386^{*}$ \\
\hline & $\Delta_{10} \mathrm{~T}_{\mathrm{SCR}}$ & $0.698^{\dagger}$ & $0.721^{\dagger}$ \\
\hline \multirow[t]{3}{*}{$\mathrm{MR}(\text { gluc })_{\mathrm{BAT}}$} & Base $T_{S C R}$ & 0.001 (NS) & $0.003(\mathrm{NS})$ \\
\hline & Peak $T_{S C R}$ (initial) & 0.002 (NS) & $0.032(\mathrm{NS})$ \\
\hline & $\Delta_{10} T_{\mathrm{SCR}}$ & 0.337 (NS) & $0.583^{*}$ \\
\hline $\begin{array}{l}{ }^{*} P<0.05 \\
{ }^{\dagger} P<0.01 \\
N S=\text { not statistica } \\
\text { Values are } r^{2}, \text { squa }\end{array}$ & Defficient for 8 male volunteers. & & \\
\hline
\end{tabular}

measures of BAT activity becomes evident. This is perhaps not surprising when videos of change in skin temperature relative to baseline are viewed (Supplemental Video 1). These show the specific warming of the supraclavicular region relative to surrounding skin temperatures and, therefore, the importance of framing the participant to include the superior portion of the sternum as a reference.

We have previously seen a greater rise in the $\mathrm{T}_{\mathrm{SCR}}$ of the right ROI (11). In addition, we show here that the outcome measures using the right ROI correlate better with BAT glucose uptake on PET/CT than do the outcome measures using the left ROI or a combined measure. The reasons merit further investigation and could be due to either anatomic or functional differences. There is no evidence of a difference in the volume of BAT between the left and right sides on PET/CT (26), but functional symmetry has not been investigated in non-IRT modalities, which could reveal whether asymmetry represents a true difference in activity or, for instance, an artifact or a slight difference in the anatomic position of BAT between the left and right sides.

Base $\mathrm{T}_{\mathrm{SCR}}$ was measured as an average of the first minute of stimulation. That $\mathrm{T}_{\mathrm{SCR}}$ is already higher in participants during the cold session demonstrates the rapidity of the BAT response to a cold stimulus. We show here that the response seen within the first $10 \mathrm{~min}$ is sufficient to ascertain an individual's BAT activity, correlating well with glucose uptake on PET/CT; however, contrary to previous reports (12), prolonged stimulation is associated with a further rise in $\mathrm{T}_{\mathrm{SCR}}$. In addition, a proper acclimatization period is essential for the accurate measurement of BAT activity using IRT and our data (not published) show that this period should be $20 \mathrm{~min}$, during which time the participant should be in the same environment and clothing as for the study and remain as still as during imaging.

The area of maximal glucose uptake on a coronal projection MIP image from ${ }^{18}$ F-FDG PET/CT closely corresponds to the warmest area within the supraclavicular ROI measured using IRT. In the 8 participants known to be BAT-positive on PET/CT, a high degree of overlap was demonstrated between the most intense glucose uptake on PET/CT and the warmest area on IRT.

The main limitation of these analyses is the small number of participants available, reducing the power to detect correlations between IRT and PET/CT outcomes. Larger studies are not ethically feasible, especially in healthy volunteers, because of the risks of exposure to the ionizing radiation associated with
PET/CT. We recommend that studies using IRT to measure BAT activity should report the right-sided ROI relative to a reference region, and authors should include a statement about the acclimatization period that was used.

Advances in IRT are allowing for more detailed assessments of changes in superficial temperature associated with changes in the underlying BAT. Radiometric sensors are becoming increasingly accurate, with some sensors now able to distinguish a change of only $0.01{ }^{\circ} \mathrm{C}$, and the resolution of images is improving, with cameras able to acquire truly high-definition images. These improvements will allow the subtler changes to be better defined, especially when combined with more sophisticated calculations of reference values for mean skin temperature. To take full advantage of these improvements, together with improvements in image acquisition rates, a fully automated analysis method should be considered. In addition, an automated standardized analysis method would reduce variability between groups. The establishment of IRT as a valid method of measuring supraclavicular BAT activity in humans will make studies feasible that until now have not been possible.

\section{CONCLUSION}

IRT provides a safe, credible, and quantifiable alternative to $\mathrm{PET} / \mathrm{CT}$ that can now be used in a wide range of population groups for the measurement of BAT activity.

\section{DISCLOSURE}

No potential conflict of interest relevant to this article was reported.

\section{ACKNOWLEDGMENTS}

The Section of Endocrinology and Investigative Medicine at Imperial College is funded by grants from the MRC, BBSRC, and NIHR; an Integrative Mammalian Biology (IMB) Capacity Building Award; an FP7-HEALTH-2009- 41592 EuroCHIP grant; and support from the NIHR Biomedical Research Centre Funding Scheme. The views expressed are those of the authors and not necessarily those of any of the funders, the NHS, the NIHR, or the Department of Health. Victoria Salem is funded by a Diabetes U.K. Harry Keen Fellowship. Waljit S. Dhillo is funded by an NIHR Research Professorship. 


\section{REFERENCES}

1. Chechi K, Nedergaard J, Richard D. Brown adipose tissue as an anti-obesity tissue in humans. Obes Rev. 2014;15:92-106.

2. Cannon B, Nedergaard J. Brown adipose tissue: function and physiological significance. Physiol Rev. 2004;84:277-359.

3. Sidossis L, Kajimura S. Brown and beige fat in humans: thermogenic adipocytes that control energy and glucose homeostasis. J Clin Invest. 2015;125:478-486.

4. Sacks HS. The importance of brown adipose tissue. N Engl J Med. 2009;361:418420.

5. Celi FS. Brown adipose tissue: when it pays to be inefficient. $N$ Engl J Med. 2009;360:1553-1556.

6. Virtanen KA, Lidell ME, Orava J, et al. Functional brown adipose tissue in healthy adults. N Engl J Med. 2009;360:1518-1525.

7. Cypess AM, Lehman S, Williams G, et al. Identification and importance of brown adipose tissue in adult humans. N Engl J Med. 2009;360:1509-1517.

8. van Marken Lichtenbelt WD, Vanhommerig JW, Smulders NM, et al. Cold-activated brown adipose tissue in healthy men. $N$ Engl J Med. 2009;360:1500-1508.

9. Roman S, Agil A, Peran M, et al. Brown adipose tissue and novel therapeutic approaches to treat metabolic disorders. Transl Res. 2015;165:464-479.

10. Vosselman MJ, Brans B, van der Lans AA, et al. Brown adipose tissue activity after a high-calorie meal in humans. Am J Clin Nutr. 2013;98:57-64.

11. Robinson L, Ojha S, Symonds ME, Budge H. Body mass index as a determinant of brown adipose tissue function in healthy children. J Pediatr. 2014;164:318-322.

12. Symonds ME, Henderson K, Elvidge L, et al. Thermal imaging to assess agerelated changes of skin temperature within the supraclavicular region co-locating with brown adipose tissue in healthy children. J Pediatr. 2012;161:892-898.

13. Salem V, Izzi-Engbeaya C, Coello C, et al. Glucagon increases energy expenditure independently of brown adipose tissue activation in humans. Diabetes Obes Metab. 2016;18:72-81.

14. Lee P, Ho KK, Lee P, Greenfield JR, Ho KK, Greenfield JR. Hot fat in a cool man: infrared thermography and brown adipose tissue. Diabetes Obes Metab. 2011;13:92-93.
15. Tattersall GJ. Infrared thermography: a non-invasive window into thermal physiology. Comp Biochem Physiol A Mol Integr Physiol. 2016;202:78-98.

16. Thermimage: thermal image analysis. The Comprehensive R Archive Network website. https://cran.r-project.org/package=Thermimage. Published March 26, 2015. Accessed December 6, 2017.

17. Gatidis S, Schmidt H, Pfannenberg CA, Nikolaou K, Schick F, Schwenzer NF. Is it possible to detect activated brown adipose tissue in humans using single-timepoint infrared thermography under thermoneutral conditions? Impact of BMI and subcutaneous adipose tissue thickness. PLoS One. 2016;11:e151152.

18. Robinson LJ, Law JM, Symonds ME, Budge H. Brown adipose tissue activation as measured by infrared thermography by mild anticipatory psychological stress in lean healthy females. Exp Physiol. 2016;101:549-557.

19. Wallis JW, Miller TR, Lerner CA, Kleerup EC. Three-dimensional display in nuclear medicine. IEEE Trans Med Imaging. 1989;8:297-303.

20. Goshtasby A. Image registration by local approximation methods. Image Vis Comput. 1988;6:255-261.

21. Ramage LE, Akyol M, Fletcher Alison M, et al. Glucocorticoids acutely increase brown adipose tissue activity in humans, revealing species-specific differences in UCP-1 regulation. Cell Metab. 2016;24:130-141.

22. Olsen JM, Csikasz RI, Dehvari N, et al. $\beta 3$-adrenergically induced glucose uptake in brown adipose tissue is independent of UCP1 presence or activity: mediation through the mTOR pathway. Mol Metab. 2017;6:611-619.

23. Scotney H, Symonds ME, Law J, Budge H, Sharkey D, Manolopoulos KN. Glucocorticoids modulate human brown adipose tissue thermogenesis in vivo. Metabolism. 2017;70:125-132.

24. Lee P, Smith S, Linderman J, et al. Temperature-acclimated brown adipose tissue modulates insulin sensitivity in humans. Diabetes. 2014;63:3686-3698.

25. Vijgen GH, Bouvy ND, Teule GJ, Brans B, Schrauwen P, van Marken Lichtenbelt WD. Brown adipose tissue in morbidly obese subjects. PLoS One. 2011;6:e17247.

26. Jang C, Jalapu S, Thuzar M, et al. Infrared thermography in the detection of brown adipose tissue in humans. Physiol Rep. 2014;2:e12167.

Immediate Open Access: Creative Commons Attribution 4.0 International License (CC BY) allows users to share and adapt with attribution, excluding materials credited to previous publications. License: https://creativecommons.org/ licenses/by/4.0/. Details: http://jnm.snmjournals.org/site/misc/permission.xhtml. 